\title{
Fasilitas Aplikasi Pendidikan dan Suasana Akademik Dapat Menciptakan Kepuasan dan Dampaknya terhadap Word of Mouth Mahasiswa
}

\author{
Wisnalmawati ${ }^{1 *}$, Wahyu Handayani ${ }^{1}$, Olinda da Conceicao ${ }^{2}$ \\ ${ }^{1}$ Faculty of Economics and Business Universitas Pembangunan Nasional "Veteran" Yogyakarta, Indonesia \\ ${ }^{2}$ Universitas Orienatal Timor Lorosae (UNITAL), Timor leste, Timor Lorosae \\ Email:wisnalupnyk@gmail.com
}

\begin{abstract}
Abstrak
Pentingnya membangun word of mouth sebagai promosi yang efisien di universitas. Tujuan penelitian ini yaitu fasilitas aplikasi pendidikan dan suasana akademik memengaruhi word of mouth, kepuasan sebagai variabel mediasi. Pendekatan riset menggunakan kuantitatif, Populasi penelitian ini adalah seluruh mahasiswa Magister Manajemen, teknik pengambilan sampel menggunakan purposive sampling dengan kriteria-kriteria tertentu. Teknik analisis yang digunakan adalah Structural Equational Model (SEM) dengan Program PLS. Hasil penelitian ini menunjukkan bahwa 1. Fasilitas aplikasi pendidikan dan suasana akademik tidak memengaruhi word of mouth. 2. Fasilitas aplikasi pendidikan dan Suasana akademik memengaruhi word of mouth yang dimediasi oleh kepuasan mahasiswa. Kebaruan dari penelitian ini adalah menciptakan kepuasan mahasiswa sehingga dapat meningkatkan word of mouth. Hasil penelitian ini dapat berkontribusi pada pengembangan model perilaku konsumen. Bagi Universitas, meningkatkan fasilitas pelatihan aplikasi pendidikan sehingga memudahkan penyimpanan soft data untuk akreditasi dan mempercepat kelulusan mahasiswa yang berkualitas sehingga tercipta kepuasan sehingga berdampak positif word of mouth
\end{abstract}

Kata kunci: Fasilitas aplikasi pembelajaran, suasana akademik, kepuasan dan word of mouth.

\begin{abstract}
The importance of building word of mouth as an efficient promotion in universities. The purpose of this study is the Educational application facilities and academic atmosphere influence word of mouth promotion, satisfaction as a mediating variable. The research approach used quantitative. The population of this study were all students of Master of Management. The sampling technique used purposive sampling with certain criteria. The analysis technique used is the Structural Equational Model (SEM) with the PLS Program. The results showed that 1. Application facilities and academic atmosphere did not affect word of mouth. 2. Application facilities and academic atmosphere influence word of mouth promotion which is mediated by student satisfaction. The novelty of this research is to create student satisfaction so that it can increase word of mouth. The results of this study contribute to the development of models of consumer behavior. For the University, improving the learning application training facilities will make it easier to store soft data for accreditation and accelerate the graduation of quality students so as to create satisfaction that has a positive impact by word of mouth.
\end{abstract}

Keywords: Learning application facilities, academic atmosphere, satisfaction and word of mouth promotion.

\section{Pendahuluan}

Menciptakan word of mouth adalah strategi promosi yang baik dan efisien. Word of mouth lebih mudah mendapatkan mahasiswa di lingkungannya. Beberapa hal positif yang dapat diambil dari promosi mulut ke mulut adalah biaya promosi yang sangat murah sehingga dapat menekan biaya secara lebih efisien, (Engel, 2006). Word of mouth adalah orang yang berbicara secara positif atau negatif tentang suatu produk atau jasa yang sedang dikonsumsi oleh pihak lain, (Haverila, Haverila, \& Twyford, 2020). Saat ini word of mouth dapat dilakukan melalui tatap muka atau dengan media sosial.

Dalam kondisi COVID-19 penting sekali peranan teknologi membantu kelancaran pendidikan. Universitas membutuhkan fasilitas aplikasi untuk menunjang keberhasilan pencapaian prodi, tidak terlepas dari fasilitas fisik maupun non fisik dalam hal teknologi seperti

\footnotetext{
${ }^{*}$ Corresponding Author
}

penyediaan wifi, e-journal, e-learning, aplikasi proses belajar mengajar. Program studi harus menyediakan fasilitas aplikasi pendidikkan berbasis teknologi yang sangat berperan penting dalam dunia pendidikkan. Fasilitas yang diberikan oleh universitas belum sepenuhnya mendukung proses belajar mahasiswa terutama pada Magister Manajemen, disebabkan selama ini belum semua Program Magister menggunakan aplikasi-aplikasi seperti program sarjana.

Fasilitas adalah segala sesuatu yang bersifat fisik dan materi, misalnya dengan tersedianya perangkat pembelajaran di ruang kelas, alat peraga, buku teks, perpustakaan, berbagai peralatan praktikum, dan segala sesuatu yang mendukung terlaksananya proses belajar mengajar. Fasilitas aplikasi pendidikan harus mencerminkan konten web dan aplikasi pembeljaran yang menarik. Konten berkaitan dengan pengorganisasian dan pengelolaan konten yang jelas serta mempermudah pencarian informasi dan konten yang berkualitas fasilitas aplikasi dapat membangun suasana yang menyenangkan 
dalam proses belajar mengajar sehingga akan mendorong mahasiswa dan dosen untuk berkarya. Suasana akademik belum ditampilkan seperti yang diharapkan, tentunya dapat mmemengaruhi suasana belajar yang nyaman di kelas.

Suasana akademik terkait dengan kondisi kelas, suasana belajar mengajar menggunakan fasilitas aplikasi pendidikan, fasilitas yang tersedia sesuai dengan tuntutan perkembangan zaman, aplikasi untuk memudahkan dalam penyimpanan dan pemeliharaan data mahasiswa dalam bentuk digital. Untuk itu diperlukan fasilitas aplikasi pendidikan agar suasana akademik dan kepuasan dapat menciptakan word of mouth yang positif. Mengingat pentingnya fasilitas aplikasi pendidikkan agar dapat membangun kepuasan mahasiswa tentunya berdampak positif dari word of mouth sehingga perlu dikaji secara ilmiah melalui penelitian ini.

Selain fasilitas aplikasi pendidikkan, suasana akademik perlu diperhatikan dalam membangun kepuasan mahasiswa. Kepuasan adalah perasaan seseorang setelah membandingkan kinerja (atau hasil) yang dia rasakan dibandingkan dengan harapannya, (Kotler \& Armstrong, 2014).

Permasalahan teoritis yang dihadapi pada perguruan tinggi adalah munculnya riset gap yang dilakukan penelitian terdahulu yaitu (Tetteh, Godson A, 2018; J. H. Kim, 2019) menunjukan hasil penelitian ada pengaruh signifikan antara fasilitas aplikasi dan Word of mouth, berbeda hasil yang dilakukan oleh Wisnalmawati (2019), fasilitas aplikasi tidak memengaruhi word of mouth. Mengapa terjadi demikian perlu pengkajian secara ilmiah.

Tujuan dari penelitian ini adalah (1) Menganalisis pengaruh fasilitas aplikasi pendidikkan berupa konten web dan aplikasi pembelajaran terhadap word of mouth. (2) Menganalisis pengaruh suasana akademik terhadap word of mouth. (3) Menganalisis fasilitas aplikasi pendidikan memengaruhi word of mouth dimediasi oleh kepuasan. (4) Menganalisis pengaruh suasana akademik terhadap word of mouth yang dimediasi oleh kepuasan mahasiswa. Kebaruan penelitian ini yaitu menciptakan kepuasan mahasiswa, dan berdampak terciptanya word of mouth positif pada pihak lain. Kontribusi penelitian mengembangkan teori perilaku konsumen (mahasiswa) dibidang pendidikan. Bagi perguruan tinggi melakukan inovasi pembelajaran dan memberikan sosialisasi.

\section{Kajian Teori}

Kotler \& Armstrong (2014) menjelaskan perilaku konsumen dibagi menjadi dua yaitu perilaku pembeli individu dan perilaku pembeli bisnis. Pembeli individu yaitu proses pembelian dilakukan konsumen untuk kebutuhan peribadi. Pembelian bisnis adalah proses pengambilan keputusan yang dilakukan oleh ang dan jasa yang perlu dibeli dan mengidentifikasi, mengevaluasi, dan memilih antara alternatif merek dan pemasok (Peter \& Olson, 1944). Dalam kehidupan sehari-hari seringkali seseorang menyampaikan informasi dari teman, keluarga, atau organisasi formal untuk menentukan kebutuhan bar kelompok tertentu dalam membeli produk atau jasa melalui sosial media.

\section{Hubungan antara Fasilitas Aplikasi dan Word of mouth}

Tetteh (2019) menjelaskan indikator fasilitas yaitu perpustakaan universitas memiliki sumber daya akademik yang memadai, universitas memiliki auditorium, ruang konferensi yang memadai, universitas memiliki fasilitas medis yang memadai, infrastruktur kampus terpelihara dengan baik. Kim (2019) menjelaskan indikator word of mouth yaitu menyampaikan pada orang lain manfaat kuliah, akan merekomendasikan magister manajemen kepada anggota keluarga, akan merekomendasikan kepada teman-teman dekat.

\section{Hubungan suasana akademik dengan Word of mouth}

Menurut Engel (1996) menjelaskan atmosfer dapat mempengaruhi perilaku konsumen dalam berperilaku word of mouth adalah perilaku konsumen. Hal ini dibuktikan dengan penelitian (Gede Mahatma Yuda Bakti \& Sumaedi, 2013). Suasana akademik menggambarkan suasana tidak bosan dalam proses pembelajaran, suasana nyaman, dan suasana akrab bersama dosen dan teman-teman.

\section{Hubungan antara Fasilitas dan kepuasan mahasiswa}

Menurut Assael (2006) fasilitas dapat mempengaruhi perilaku konsumen, sedangkan word of mouth merupakan bentuk perilaku yang dilakukan secara khusus. Hal tersebut dibuktikan dengan penelitian (Talukder, Chiong, Bao, \& Hayat Malik, 2019).

\section{Hubungan antara suasana akademik dan kepuasan}

Watanabe, Alfinito, Curvelo, \& Hamza (2020) membuktikan kepuasan konsumen di sebuah toko. Toko tempat kesenangan konsumen. Kepuasan terkait interaksi mahasiswa antara mahasiswa (Eldegwy, Elsharnouby, \& Kortam, 2018).

\section{Hubungan kepuasan dengan word of mouth.}

Menurut Engel, (1996) menjelaskan kepuasan dapat mempengaruhi perilaku konsumen dalam berperilaku word of mouth. Hal ini dibuktikan dengan penelitian (Gede Mahatma Yuda Bakti \& Sumaedi, 2013). Secara keseluruhan ada kepuasan dalam kegiatan kemahasiswaan, kegiatan kemahasiswaan telah memenuhi ekspektasinya dan kegiatan kemahasiswaan telah memenuhi kebutuhannya, (Eldegwy et al., 2018; Ilyas \& Zaman, 2020; Trivedi \& Yadav, 2020).

\section{Metode}

Rancanganan penelitian ini adalah rancangan penelitian kuantiatif yaitu menggunakan alat statistik. Jenis data yang digunakan adalah data primer, yaitu informasi dikumpulkan dari responden langsung.

Populasi penelitian ini adalah seluruh mahasiswa Magister Manajemen dari empat perguruan tinggi di Indonesia. Teknik sampel dalam penelitian ini menggunakan metode nonprobability sampling dengan teknik purposive sampling. Definisi purposive sampling menurut (Sugiyono, 2013) adalah teknik penentuan sampel dengan pertimbangan tertentu. Teknik pengambilan sampel dalam penelitian ini 
yaitu dengan mempertimbangkan kriteria yaitu responden merupakan mahasiswa Magister Manajemen aktif dan telah menjadi Mahasiswa Magister Manajemen minimal satu tahun.

Teknik analisis yang digunakan adalah Structural Equational Model (SEM) dengan Program Partial Leas Square (PLS). Sampel minimum dalam model PLS adalah 30, dan tidak ada batasan sampel maksimum. Pendapat Hair et al. (2014), besarnya sampel bila terlalu besar akan menyulitkan untuk mendapat model yang cocok, dan disarankan ukuran sampel yang sesuai agar dapat digunakan estimasi interpretasi dengan SEM PLS. Lebih lanjut Hair et al. (2014) menyatakan bahwa jumlah sampel yang respretantif untuk menggunakan SEM/PLS adalah 100-200. Berdasarkan jumlah sampel minimal yang harus diambil dalam penelitian ini dan adanya saran dari Hair et al. (1998) yang menyebutkan bahwa jumlah sampel dalam analisis SEM PLS adalah sebesar 100 dan jumlah maksimalnya yaitu 200 .

Dalam penelitian ini dilakukan pengujian validitas dan reliabilitas. Nilai $r>0,3$ maka item penelitian dikatakan valid.

Tabel 1. Validitas dan Reliabilitas

Variabel/sumber Item indikator Loading Realiabel

\begin{tabular}{llll} 
& & \multicolumn{3}{c}{ faktor } & \\
\hline Fasilitas aplikasi & $\mathrm{X} 11$ & 0,799 & 0,841 \\
pendidikan Engel & $\mathrm{X} 12$ & 0,902 & \\
(1996);Sumaedi.et. & $\mathrm{X} 13$ & 0,917 & \\
al (2012); Talukder, & & & \\
Md Shamim (2018) & & & \\
\hline Suasana akademik & $\mathrm{X} 21$ & 0,836 & 0,842 \\
Engel(1996);Sumae & $\mathrm{X} 22$ & 0,896 & \\
di. et.al (2012); & $\mathrm{X} 23$ & 0,796 & \\
$\begin{array}{l}\text { Talukder, Md } \\
\text { Shamim (2018) }\end{array}$ & $\mathrm{X} 24$ & 0,767 & \\
Kepuasan & & & \\
mahasiswa & $\mathrm{Z} 11$ & 0,812 & 0,837 \\
Subrahmanyam & $\mathrm{Z} 12$ & 0,826 & \\
(2016) & $\mathrm{Z} 13$ & 0,836 & \\
Word of mouth & $\mathrm{Y} 11$ & 0,809 & \\
$\begin{array}{l}\text { Engel (1996); } \\
\text { Talukder, Md }\end{array}$ & $\mathrm{Y} 12$ & 0,734 & 0,822 \\
Shamim (2018); & $\mathrm{Y} 13$ & 0,920 & \\
Kim, Yun-Hee. & & & \\
(2018) & & & \\
\hline Sumber: data primer, 2020 & & & \\
\hline
\end{tabular}

Sumber: data primer, 2020

Jika nilai Cronbach alpha > 0,7 dinyatakan reliabel.

\section{Hasil dan Pembahasan}

\section{Hasil penelitian deskriptif}

Hasil penelitian deskriptif dapat dilihat pada Tabel 2 yaitu rata-rata indicator variable peelitian fasilitas aplikasi, atmosfer akademik, kepuasan dan word of mouth.

Hasil deskriptif menunjukan rata-rata fasilitas aplikasi yang berkaitan dengan pembelajaran masih rendah, pelu ditingkatkan. Dalam pelaksanaan mahasiswa perlu memberi sosialisasi yang jelas karena aplikasi selalu terjadi inovasi-inovasi sehingga mahasiswa terlambat mendapatkan informasi.
Tabel 2. Rata-rata indikator

\begin{tabular}{lcc}
\hline \multicolumn{1}{c}{ Variabel/sumber } & Item indikator & Mean \\
\hline Fasilitas aplikasi & $\mathrm{X} 11$ & 3,5000 \\
pendidikan, Engel & $\mathrm{X} 12$ & 3,7500 \\
(1996);Sumaedi.et.al & $\mathrm{X} 13$ & 3,6700 \\
(2012); Talukder, Md & & \\
Shamim (2018) & & \\
\hline Suasana akademik & $\mathrm{X} 21$ & 4,0900 \\
Engel(1996);Sumaedi.et. & $\mathrm{X} 22$ & 4,1500 \\
al (2012); Talukder, Md & $\mathrm{X} 23$ & 4,1100 \\
Shamim (2018) & $\mathrm{X} 24$ & 4,1800 \\
\hline Kepuasan mahasiswa & $\mathrm{Z} 11$ & 4,0500 \\
Subrahmanyam (2016) & $\mathrm{Z} 12$ & 4,0500 \\
\multicolumn{2}{l}{ Z13 } & 4,1000 \\
Word of mouth (2018); & $\mathrm{Y} 13$ & 4,1400 \\
Engel (1996); Talukder, & $\mathrm{Y} 12$ & 4,0900 \\
Md Shamim (2014 & & 4,0900 \\
Kim, Yun-Hee. (2018) & &
\end{tabular}

Kim, Yun-Hee. (2018)

Sumber: data primer, 2020

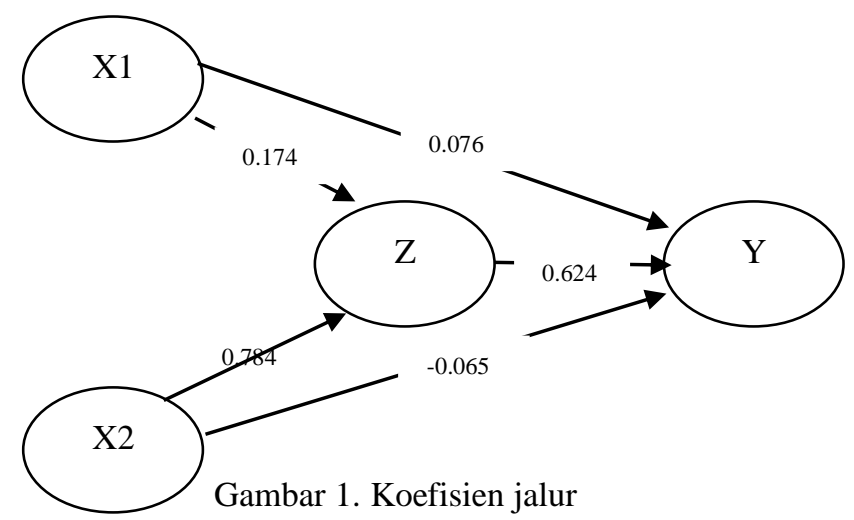

Tabel 3. Koefisien Jalur

\begin{tabular}{ccc}
\hline Variable & Coeficience & Significance \\
\hline X1-Y & 0,076 & 0,568 \\
X2-Y & $-0,065$ & 0,671 \\
X1-Z & 0,174 & 0,000 \\
X2-Z & 0,784 & 0,000 \\
Z-Y & 0,624 & 0,000 \\
\hline
\end{tabular}

Sumber: data primer, 2020

Berdasarkan Tabel 3 terlihat bahwa:

Fasilitas aplikasi pembelajaran tidak secara langsung mempengaruhi word of mouth, koefisien jalurnya adalah 0,076, dengan (P-value $=0,568)$ lebih besar dari 0,05. Atmosfer akademik tidak secara langsung mempengaruhi word of mouth, koefisien jalurnya adalah -0,065 (P-value $=0,671)$ lebih besar dari 0,05.

Fasilitas aplikasi pembelajaran memengaruhi kepuasan mahasiswa, koefisien jalurnya adalah 0,174 (P-value $=$ 0,000) lebih kecil dari 0,05. Atmosfer akademik memengaruhi kepuasan mahasiswa, koefisien jalurnya adalah 0,784 $(\mathrm{P}$-value $=0,000)$ lebih kecil dari 0,05.

Kepuasan mahasiswa mempengaruhi word of mouth, koefisien jalurnya adalah 0,624 (P-value $=0,000)$ lebih kecil dari 0,05. Bila dicermati ada 2 jalur yang tidak signifikan yaitu fasilitas aplikasi pembelajaran dan atmosfer akademik terhadap word of mouth. 


\section{Pembahasan}

Pengujian hipotesis pertama yaitu fasilitas aplikasi pendidikkan tidak berhubungan secara signifikan dengan word of mouth (H1 tidak terbukti). Aplikasi yang disediakan untuk yang baru penerimaan mahasiswa, penyimpanan data yang memadai, dan penyimpanan administrasi berbasis digital. Hal ini tidak mendukung word of mouth. Penelitian ini tidak mendukung teori dan penelitian yang disebut Talukder, Md Shamim (2018); Tetteh, Godson A (2018) ; M. J. Kim, Chung, \& Lee (2011); Mallika Appuhamilage \& Torii (2019); Engel (1996). fasilitas aplikasi tidak mempengaruhi mahasiswa dari mulut ke mulut. Semua hal yang biasa diperoleh mahasiswa dilakukan oleh siswa dengan sistem manual tetap positif karena yang dituntut oleh mahasiswa dalam proses pembelajaran di Magister Manajemen adalah suasana akademik yang kondusif, sehingga akan tercipta dari word of mouth yang positif.

Pengujian hipotesis kedua: Suasana akademik tidak memengaruhi word of mouth. (H2 tidak terbukti). Hasil temuan ini tidak mendukung teori dan kajian empis yang dikemukakan yaitu Kanuk (2010); Gede Mahatma Yuda Bakti \& Sumaedi (2013); J. H. Kim (2019); Assael (2006); Engel (1996); Eldegwy et al. (2018). Muncul pertanyaan mengapa hal ini terjadi ?. memperkuat hasil ini peneliti melakukan wawancara pada beberapa mahasiswa yang bersedia member tanggapan. Hasil wawancara suasana akademik seraca fisik tidak begitu penting, tetapi suasana secara virtual pada masa COVID19, bagaimana dosen memberikan suasana belajar tidak membosankan.

Pengujian hipotesis ketiga; kepuasan sebagai mediasi antara pengaruh fasilitas aplikasi pendidikan terhadap word of mouth, (H3 terbukti). Dalam hal ini pengaruh fasilitas aplikasi pendidikan tidak berpengaruh secara signifikan secara langsung, otomatis kepuasan dalam model penelitian ini adalah mediasi sehingga kepuasan merupakan variabel penting yang perlu diciptakan pada Magister Manajemen.

Kepuasan mahasiswa yang terbukti harus diciptakan agar dapat menciptakan word of mouth mahasiswa. Kepuasan terkait dengan kepuasan terhadap kelancaran bimbingan tesis oleh dosen, kepuasan terhadap materi yang diajarkan dosen, ketersediaan fasilitas aplikasi untuk mendapatkan informasi, dan kepuasan kelulusan sesuai target dalam kurikulum.

Hasil ini mendukung penelitian Fasiltas memengaruhi loyalitas dimediasi oleh kepuasan, (Liang, 2019; Mallika Appuhamilage \& Torii, 2019; Anouze \& Alamro, 2019) perceived usefulness, perceived ease of use, security and privacy memengaruhi tidak langsung intention to use dimediasi oleh sikap. Menguji hipotesis keempat; kepuasan mahasiswa sebagai mediasi antara pengaruh suasana akademik terhadap word of mouth, H4 terbukti.

Dalam hal ini pengaruh atmosfer akademik tidak berpengaruh signifikan terhadap word of mouth, dapat dikatakan kepuasan sebagai variabel mediasi sehingga kepuasan menjadi variabel penting. Kepuasan harus diciptakan untuk menciptakan word of mouth mahasiswa, kepuasan terkait dengan kepuasan atas kelancaran bimbingan tesis oleh dosen, kepuasan dengan dosen tentang materi yang diajar, tersedianya fasilitas aplikasi untuk mendapatkan informasi, dan kepuasan kelulusan sesuai dengan yang ditargetkan dalam kurikulum. Hasil penelitian ini menunjukan peripheral services memegaruhi experience quality, sehingga berdampak terhadap student involvement student, (Dassanayake \& Senevirathne, 2018) Penelitian ini menunjukkan pengalaman-pengalaman mahasiswa dapat meningkatkan keterlibatan mahasiswa dalam kegiatan-kegiatan pembelajaran. (Eldegwy et al., 2018) perlu menciptakan kepuasan mahasiswa di universitas.

Keakuratannya penelitian ini dapat dilihat Q2 yang menunjukan fit model.

Koefisien Determinasi ( $R$ square)

Suasana akademik $(\mathrm{R} 21)=0,799$

Word of mouth $(\mathrm{R} 22)=0,380$

Relevansi prediktif Q2

$\mathrm{Q} 2$ = 1 - (1-R21) (1-R22)

$$
\begin{aligned}
& =1-(1-0,799)(1-0,380) \\
= & 1-(0,201)(0,620) \\
= & 1-0,1246 \\
= & 0,8754
\end{aligned}
$$

Q2 adalah $87.54 \%$, dimana fasilitas aplikasi, suasana dan kepuasan mahasiswa memberikan kontribusi $87.54 \%$ terhadap word of mouth mahasiswa, sisanya $12.46 \%$ dipengaruhi oleh variabel lain yang tidak dapat dideteksi oleh model PLS.

\section{Simpulan dan Implikasi Penelitian}

Hasil pembahasan menunjukkan bahwa fasilitas aplikasi pendidikan berkaitan dengan konten web dan aplikasi pembelajaran dan suasana akademik tidak mempengaruhi word of mouth, fasilitas aplikasi pendidikkan dan suasana akademik mempengaruhi word of mouth dimediasi oleh kepuasan mahasiswa. Dengan kata lain penelitian ini menunjukkan bahwa fasilitas aplikasi pendidikan dan suasana akademik tidak berpengaruh langsung terhadap word of mouth. fasilitas aplikasi pendidikan yang berkaitan dengan penerimaan mahasiswa baru, penyimpanan data yang memadai, dan kemudahan administrasi berbasis digital. Suasana akademik yang terkait dengan suasana akademik program studi Magister Manajemen menawarkan proses pembelajaran yang harmonis, suasana kesenangan, suasana kenyamanan belajar, dan suasana keseruan bersama dosen dan sahabat dapat meningkatkan word of mouth mahasiswa. Artinya pentingnya membagun kepuasan yang dirasakan mahasiswa sehingga dapat meningkatkan pembicaraan positif dengan pihak lain.

Kontribusi teori tersebut adalah untuk mengembangkan teori-teori perilaku konsumen khususnya fasilitas aplikasi web dan suasana akademik yang dapat meningkatkan kepuasan mahasiswa dalam proses pembelajaran sehingga berdampak pada word of mouth mahasiswa disisi lain. Kontribusi praktis bagi magister manajemen untuk mengembangkan strategi dalam membangun kepuasan untuk meningkatkan word of mouth yaitu dengan memfasilitasi bimbingan tesis oleh dosen, kepuasan terhadap materi yang diajarkan dosen, tersedianya 
fasilitas aplikasi untuk mendapatkan informasi, dan kepuasan kelulusan sesuai dengan yang ditargetkan. dalam kurikulum.

\section{Ucapan Terima Kasih}

Tim penulis mengucapkan terima kasih kepada :

a. Ketua LPPM yang memberi kesempatan dalam penelitian lembaga, November 2019, sehingga penelitian ini merupakan pengembangan dari penelitian lembaga, dimplementasikan pada obyek yang lebih luas.

b. Terima kasih pada mahasiswa yang terlibat dalam membantu pengumpulan data.

\section{Referensi}

Anouze, A. L. M., \& Alamro, A. S. (2019). Factors affecting intention to use e-banking in Jordan. International Journal of Bank Marketing, 38(1), 86112. https://doi.org/10.1108/IJBM-10-2018-0271

Chernatony, I. B. and E. M. L. de. (2013). The influence of brand equity on consumer responses. Journal of Consumer Marketing, 30/1, 62-74. https://doi.org/10.1108/07363761311290849

Dassanayake, H. C., \& Senevirathne, A. (2018). Impact of e-servicescapes on student engagement: mediating impact of experience quality. Asian Association of Open Universities Journal, 13(2), 203-222. https://doi.org/10.1108/aaouj-11-20180024

Dölarslan, E. S. (2014). Assessing the effects of satisfaction and value on customer loyalty behaviors in service environments High-speed railway in Turkey as a case study. Management Research Review, $37 \quad$ No. 8(8), 706-727. https://doi.org/10.1108/MRR-06-2013-0152

Eldegwy, A., Elsharnouby, T. H., \& Kortam, W. (2018). How sociable is your university brand? An empirical investigation of university social augmenters' brand equity. International Journal of Educational Management, 32(5), 912-930. https://doi.org/10.1108/IJEM-12-2017-0346

engel. (2006). Sustainable food consumption: Exploring the consumer "attitude - Behavioral intention" gap. Journal of Agricultural and Environmental Ethics, 19(2), 169-194. https://doi.org/10.1007/s10806-0055485-3

Forney, M.-Y. L. Y.-K. K. L. P. D. K. J. (2008). Factors affecting Mexican college students' purchase intention toward a US apparel brand. Journal of Fashion Marketing and Management, 12(3), 294307. https://doi.org/10.1108/03090560410539302

Gede Mahatma Yuda Bakti, I., \& Sumaedi, S. (2013). An analysis of library customer loyalty:The role of service quality and customer satisfaction, a case study in Indonesia. Library Management, 34(6-7), 397-414. https://doi.org/10.1108/LM-05-2012-0025

Haverila, M., Haverila, K., \& Twyford, J. C. (2020). Identification of key variables and constructs in the context of wine tasting room: importanceperformance analysis. International Journal of Wine Business Research. https://doi.org/10.1108/IJWBR02-2020-0006

Ilyas, A., \& Zaman, M. K. (2020). An evaluation of online students' persistence intentions. Asian Association of Open Universities Journal, 15(2), 207-222. https://doi.org/10.1108/aaouj-11-20190053

Kim, J. H. (2019). Imperative challenge for luxury brands: Generation Y consumers' perceptions of luxury fashion brands' e-commerce sites. International Journal of Retail and Distribution Management, $\quad 47(2), \quad 220-244$. https://doi.org/10.1108/IJRDM-06-2017-0128

Kim, M. J., Chung, N., \& Lee, C. K. (2011). The effect of perceived trust on electronic commerce: Shopping online for tourism products and services in South Korea. Tourism Management, 32(2), 256-265. https://doi.org/10.1016/j.tourman.2010.01.011

Kotler, P., \& Armstrong, G. (2014). Pengaruh Bauran Pemasaran Terhadap Keputusan Pembelian Rokok MILD. Jurnal Ecodemica: Jurnal Ekonomi, Manajemen, Dan Bisnis.

Liang, C. C. (2019). Solo economy in Taiwan: a quality study of click-and-mortar malls. Asia Pacific Journal of Marketing and Logistics. https://doi.org/10.1108/APJML-05-2018-0188

Mallika Appuhamilage, K. S., \& Torii, H. (2019). The impact of loyalty on the student satisfaction in higher education. Higher Education Evaluation and Development, 13(2), 82-96. https://doi.org/10.1108/heed-01-2019-0003

Peter, J. P., \& Olson, J. C. (1944). Consumer Behavior \& Marketing Strategy Ninth Edition. 578.

Sharma, P. (2012). Offshore outsourcing of customer services - boon or bane? Journal of Services Marketing, 26/5, 352-364. https://doi.org/10.1108/08876041211245272

Talukder, M. S., Chiong, R., Bao, Y., \& Hayat Malik, B. (2019). Acceptance and use predictors of fitness wearable technology and intention to recommend: An empirical study. Industrial Management and Data Systems, 119(1), 170-188. https://doi.org/10.1108/IMDS-01-2018-0009

Tetteh, G. A. (2019). Evaluating university leadership performance using Lean Six Sigma framework. International Journal of Lean Six Sigma, 10(4), 1018-1040. https://doi.org/10.1108/IJLSS-05-20180051

Trivedi, S. K., \& Yadav, M. (2020). Repurchase intentions in Y generation: mediation of trust and esatisfaction. Marketing Intelligence and Planning, $38(4)$, 401-415. https://doi.org/10.1108/MIP-022019-0072

Watanabe, E. A. de M., Alfinito, S., Curvelo, I. C. G., \& Hamza, K. M. (2020). Perceived value, trust and purchase intention of organic food: a study with Brazilian consumers. British Food Journal, 122(4), 1070-1184. https://doi.org/10.1108/BFJ-05-20190363 